\title{
Impact of Financial Knowledge and Investment Experience on Investment Decision Making with and without Risk Tolerance Mediation
}

\author{
Muhammad Aslam ${ }^{1}$, Muhammad Faisal Gulzar ${ }^{1}$, Muhammad Aamir Shahzad ${ }^{2, *}$, Muhammad \\ Muarif Maqbool ${ }^{1} \&$ Muhammad Hassan Chaudhary ${ }^{3}$ \\ ${ }^{1}$ School of Commerce \& Accountancy, Minhaj University Lahore, Pakistan \\ ${ }^{2}$ College of Economics and Management, Huazhong Agricultural University, Wuhan \\ (430070), P. R., China \\ ${ }^{3}$ Department of International Relations, National Defence University, Islamabad, Pakistan \\ *Corresponding author: College of Economics and Management, Huazhong Agricultural \\ University, No. 1 Shizishan Street, Hongshan District, Wuhan (430070), P. R., China. E-mail: \\ muhammadamir_11@pide.edu.pk
}

Received: April 29, 2020 Accepted: May 31, 2020 Published: August 25, 2020

doi: 10.5296/erm.v6i1.16930ＵRL: https://doi.org/10.5296/erm.v6i1.16930

\begin{abstract}
This research will explore the relationship between financial knowledge, investment experience, and investment decision making. The primary dataset was obtained from the investors in Pakistan stock exchange located in the city of Lahore, Punjab, Pakistan. The random sampling technique was used for the respondent selection. The comprehensive questionnaire contains the nominal, ordinal categorical scales for a survey response. The normality \& reliability of the data were further verified by the statistical tests. The results estimated using the multiple regression analysis will be revealed in this study. This research will study the impact of the financial knowledge on investment decision making with and without the financial risk tolerance. Financial risk tolerance plays a mediating role during the process.
\end{abstract}

Keywords: investment experience, financial knowledge, risk tolerance, investment decision-making, investor 


\section{Introduction}

The investment decision-making process depends upon various factors that may vary among individual to individual. The procedure of basic leadership turns out to be simple when all the bewildering factors are all around perceived by financial specialists. Speculators' experience exceedingly complex factors like; Risk, uncertainty, and decision over-burden. Speculators need to pursue Risks in their budgetary decision. This can lead them to procure benefits. Then again, any choice made by speculators based on poor or deluding data or based on ineffectively investigated data may lead towards defective results (Bannier, C. E., \& Neubert, M. 2016)

Financial investment behavior to various factors and challenges come upon having a great effect on danger recognition and speculation alternatives. So the cash related training and task encounter have to be the vital elements having sway on Risk resilience and speculation decisions. Because the information used to decide budgetary selections is being accumulated from various assets. The conventional hypothesis of back recommended, while settling on a decision about the venture, individuals are more normal, it implies they put just in those decisions which give them higher returns and increment their riches. Be that as it may, as per behavioral back, individuals are not reasonable, but rather they are silly or ordinary. They can't generally settle on those decisions which are better for them. Although, occasionally they use sound judgment and settle on the terrible decision on the other time. This is a more reasonable behavioral back hypothesis than the past hypothesis which is a customary hypothesis. The inquiry emerges that why individuals are irrational (Bens, D. A., \& Monahan, S. J. 2008) The OECD 2011 inspects the level of financial knowledge. The examination discovered that budgetary education level is generally low for the respondents in the UK, European nations, the USA, Australia and Japan (Bryman, A., 2011)

Another research by Grable, J. E., \& Roszkowski, M. J., (2007) they took the examples from the urban communities Investors. They anticipated the variables affecting speculators' conduct are money related execution, Share's long haul execution, expected payout Lucarelli et al., (2015) concluded that individuals with less monetary proficiency will influence their budgetary basic leadership particularly in their speculation choice.

However, the literature is extensively vast, so far; to the best of our knowledge, no study attempted to find the impact investment experience, financial knowledge with the mediating role of risk tolerance on investment decisions. The investors who know about financial knowledge, investment experience, and dare to take risky decisions make rational decisions than otherwise.

This study will also help investors to see the impact of financial knowledge, risk tolerance level, and investment experience on rising in profitability and gain earned by investors in uncertain situations. A very little attention has been given in Pakistan to determine these factors which affect financial investment decision making.

This paper contributes to the existing literature in three different angles. First, it examines the impact of financial knowledge and risk tolerance on investment decisions. Second, it provides 
investigations of investment experience and risk tolerance for investment decision making. Third, it extends the literature regarding the relationship of financial knowledge and investment experience on decision making considering the mediating role of risk tolerance.

The subsequent section describes the literature review and section 3 presents the methodology. Section 4 provides the data analysis, while section 5 presents discussions, while section 6 concludes the study.

\section{Literature Review}

A couple of studies on the impact of financial knowledge have focused on the association between financial knowledge and wanders decisions. Late research focuses on the assessment of the components that affect wanders decision making, these researches utilized the behavioral back theory rather than relying on the standard store speculation (Blessing, S., 2011). The researches in Australia, the USA, and the UK evaluated the financial knowledge and socioeconomic factors. These depict that the socioeconomic characteristic factors affect financial knowledge. The research by Lusardi, A., (2008) examines the financial knowledge of adults on subjects related to singular reserve. The examination revealed that, less fiscally capable respondents will likely be single, such as uneducated, low pay, minority, and either energetic or old (not tolerably matured) (Shoji, I., \& Kanehiro, S., 2012)

The Grable, J. E., \& Roszkowski, M. J. (2007) compare financial knowledge and revealed that there are assortments in financial knowledge level transversely finished size and money related social events. A difference exists in size and budgetary social occasions

The study by Harris et al., (1994) who take a look at wander guidance of 530 online cash related axecs for Australia. They find that the extent of wandering functionality adjusts with human beings' socioeconomic like coaching, facets, age, pay, and sexual advent. For example, ladies have overall decreased wander schooling than guys and extra prepared people perform better than energetic people. Sexual creations also have an effect on at the financial understanding.

Observational outcomes propose that respondents with more trust in their budgetary learning demonstrate a higher degree to design. Monetary lack of education is high among the particular age group, sex, salary, and capability. Cottin, J., (1995) research on less training and less money-related refinement additionally appears in fewer age respondents. Monetary absence of education has critical outcomes; the individuals who need proficiency won't have the capacity to make retirement plans. Chen, L. a., (2015) shows that fewer riches close to the retirement age will have less capacity to keep resources into stocks and will obtain at high financing costs. Boisclair et al., (2017) demonstrates that less skill of money related training is exceptionally normal and individuals don't know about even essential measurements that are identified with Economics. So to accomplish potential outcome monetary knowledge is essential.

The earlier researches conducted to only see the determinants of socioeconomic factors on 
investment decisions making in some countries of Asia excluding Pakistan. Moreover, studies are conducted in investor rationality and stock market volatility. But the behavioral factors of investors in the decision-making process which depend on demographics, income level, financial knowledge, and previous investment experience but their effect yet not find in Pakistan.

\section{Methodology}

\subsection{Data Collection}

The target population for this study is the investors in the stock market of Pakistan. The random sampling techniques were used due to its efficiency and cost-effectiveness. The sample size was determined by the thumb rule. A total of 250 respondents were selected for this survey. The data was collected through a structured questioner, which contains 25 structured questions pertaining to investment decisions, financial knowledge, risk tolerance, and investment experience.

\subsection{Study Model}

The (Explanatory) independent variables are financial knowledge and investment experience, whereas the investment decision making represents the dependent variable. However, financial risk tolerance plays a mediation role in this model. See figure.

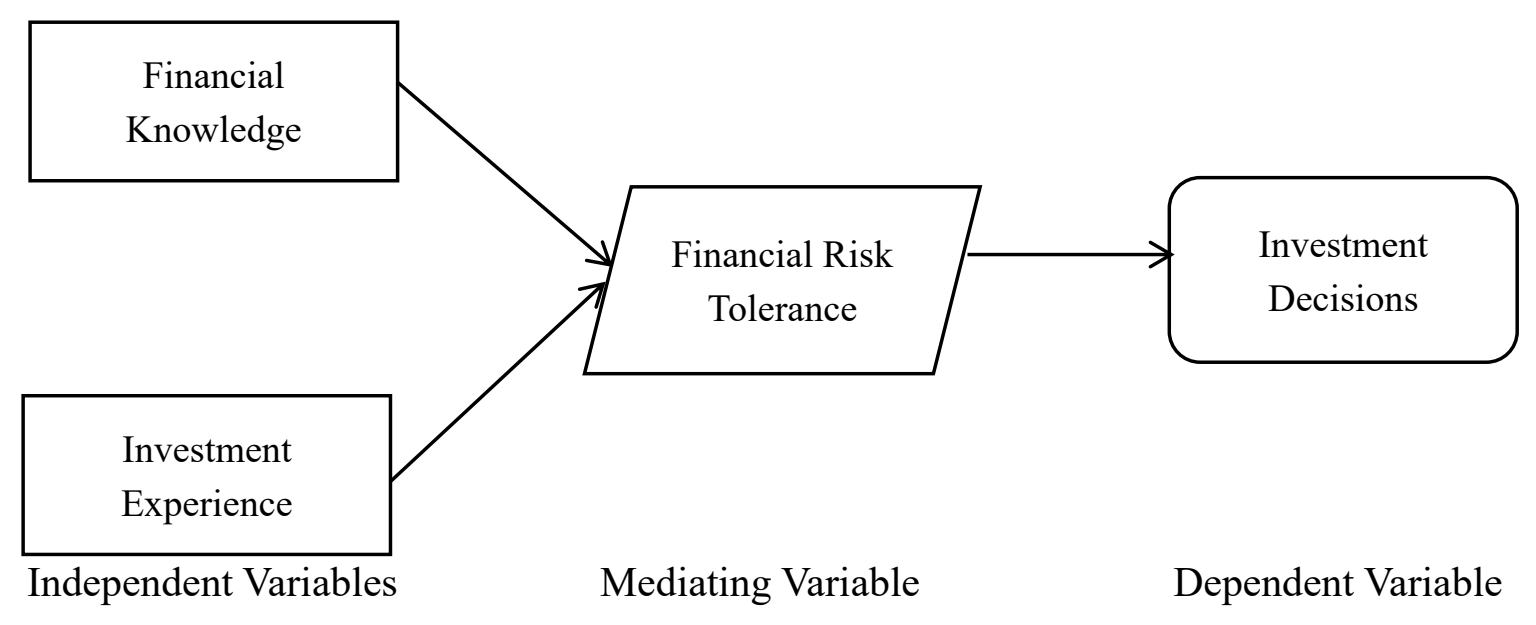

\subsection{Econometric Specification}

The multiple regression models are used for the estimation of the results. The econometric specification of the model is given below;

$\mathrm{Y}=\alpha+\beta \mathrm{x}$

$\mathrm{X}=\beta 0+\beta 1 \mathrm{FK}+\beta 2 \mathrm{IV}+\beta 3 \mathrm{FRT}+\varepsilon$

Whereas; $\mathrm{Y}=$ Investment Decision $\mathrm{X}=$ Factors affecting Investment Decision, $\mathrm{FK}=$ Financial Knowledge, IE $=$ Investment Experience, FRT $=$ Financial Risk Tolerance, ID $=$ Investment Decision. 
The study considers the risk tolerance as the mediating variable. This research will try to find the: 1) impact on the investment decision making against the alternative proposition, taking into account the risk tolerance mediating role. Moreover, 2) the proposition investment experience have no impact on the investment decision making against the alternative hypothesis considering the risk mediating variable role.

\section{Data analysis}

The sample size is 250 respondents. The descriptive statics show that the average value of the investment decision making is 1.11 . Moreover, the average values of the financial decision are 1.43. While the investors that possess an average of 10 years' experience in the investment. However, the risk tolerances mean value of 3.46. See Table 1 for details. The results were estimated using computer software SPSS.

Table 1. Descriptive Statistics

\begin{tabular}{lllllllllll}
\hline \multicolumn{1}{c}{ Descriptive Statistics } \\
\hline Variables & $\mathrm{N}$ & Min & Max & Mean. & S.D & Skewnes & & Kurtosis \\
& Statistic & Statistic & Statistic & Statistic & Statistic & Statistic & S.E & Statistic & S.E \\
\hline $\begin{array}{l}\text { Investment. } \\
\text { Decisions }\end{array}$ & 250 & 1 & 1.5 & 1.1191 & 0.13882 & 0.242 & 0.154 & -0.143 & 0.307 \\
$\begin{array}{l}\text { Financial. } \\
\text { Knowledge }\end{array}$ & 250 & 1.12 & 3.2 & 1.4342 & 0.17175 & 0.561 & 0.154 & 0.859 & 0.307 \\
$\begin{array}{l}\text { Investment } \\
\text { Experiences }\end{array}$ & 250 & 1 & 33 & 10.364 & 8.98456 & 0.905 & 0.154 & -0.216 & 0.307 \\
Risk. Tolerance & 250 & 1 & 3.46 & 2.1174 & 0.67674 & 0.39 & 0.154 & -1.054 & 0.307 \\
\hline
\end{tabular}

The investor with the lowest overall risk scores 1 and the participant with the highest total risk received scores of 3.46. The value of financial knowledge lies between $0-3$. The study performed the Pearson correlation(note 1) if the value of correlation coefficients lies greater than 0.7 and lower than -0.7 then the multicollinearity problem exists in the data. This study is free of such problems.

\subsection{Regression Analysis With-Out Mediation}

The results show that with-out mediation wherein $\mathrm{R}$ square suggests a $48 \%$ variance in investment decision making is as a result of the independent variable. The results estimated using multiple linear regressions indicate that the model is a good fit. The value of F-statistics is 14.14 at 95 level of confidence. The significance value is .046 less than 0.05 therefore the research rejects the null hypothesis. The effect of financial knowledge and investment experience with risk tolerance on financial decision making exists. The results indicate that the negative association exists between the investment decision making and the financial knowledge with -0.38 value of the coefficient. Whereas the investment experience coefficient 
is positively associated with investment decision making, the coefficient value 0.069 .

\subsection{Regression Analysis with-Mediation}

The results revealed that with mediation wherein the $\mathrm{R}$ square value $38 \%$ variance in investment decision making and risk is due to the independent variable. The results estimated using multiple linear regressions indicate that the model is a good fit. The value of F-statistics is 4.24 at 95 level of confidence. Furthermore, the results revealed that the negative association exists between the investment decision making and the financial knowledge with -1.39 value of the coefficient. On the other hand, the investment experience coefficient is positively associated with investment decision making, coefficient value 0.018 . The financial risk tolerance also has a significant impact on investment decision making with p-value 0.033 and a coefficient value of 0.249 with a standard error of 0.018 . These results indicate that there is a partial mediation exists in financial knowledge and investment experience with investment decisions making. The study null hypothesis is rejected and the alternative hypothesis is accepted which shows that these variables have a significant impact on investment decision-making of financial behavior of investors.

Table 2. Regression Analysis with Mediation

\begin{tabular}{lccccc}
\hline Variable & Coefficient & Std. Error & t-Statistic & Prob. & Results \\
\hline Constant & 2.176 & 0.082 & 13.368 & 0.000 & significant \\
Financial Knowledge & -1.39 & 0.051 & -0.029 & 0.652 & insignificant \\
Investment Exp & 0.018 & 0.001 & -2.229 & 0.027 & significant \\
Risk Tolerance & 0.249 & 0.018 & 2.311 & 0.022 & significant \\
Diagnostics & & & & \\
R-Square & .380 & Adjusted R-squared & & .362 & .008 \\
F-statistic & 4.24 & Prob(F-statistic) & & \\
\hline
\end{tabular}

\section{Discussion}

The results of the analysis in which correlation and regression evaluation indicate that financial knowledge has insignificant while the investment experience has a positive significant effect on investment decision making by investors with the consideration of risk tolerance. The null hypothesis is rejected in case of risk tolerance and investment experience, whereas financial knowledge has an insignificant impact on investment decisions.

\section{a. Proposition \# 1}

The impact of financial knowledge of investment decision without risk tolerance: Extensive analysis revealed that financial knowledge is positively correlated with the investment decision making without the mediation of risk tolerance. Without risk mediation, the $\mathrm{R}$-square value is .48. 


\section{b. Proposition \# 2}

Investment experience has impacted investment decisions due to risk tolerance: Under risk tolerance, the relationship becomes stronger between financial knowledge and investment decision making i.e. $53 \%$. The R-square value reduced to 0.38 . Moreover, the model is significant at a $95 \%$ confidence level.

The financial knowledge is important for managing private finances through appropriate short-term decision-making (Hastings et al., 2012). And this is also important for changing financial conditions. This gives insights to the investors to move for economic selection. The study by (World Bank, 2011) indicates financial knowledge is essential for investors to utilize character again related records. This study supports the proposition that financial knowledge impacts investment decision with risk tolerance.

\section{Conclusion}

This study has practical implications for the investors regarding the decision-making for investment decisions. It also has an addition to the existing literature in various aspects such as it provides important insights to the individual investors about the investment decision making considering the risk factor, financial knowledge, and investment experience. Moreover, this study bridges the gap in the existing literature on investment decision making, financial knowledge, and financial risk tolerance. It also suggests researches to dig out this important issue on investment decision making in other countries too. The study had the limitation of funds availability.

\section{References}

Bannier, C. E., \& Neubert, M. (2016). Gender differences in financial risk taking: the role of financial literacy and risk tolerance. Economics letters, 145, 130-135. https://doi.org/10.1016/j.econlet.2016.05.033

Bens, D. A., \& Monahan, S. J. (2008). Altering investment decisions to manage financial reporting outcomes: asset-backed commercial paper conduits and fin 46. Journal of accounting research, 46(5), 1017-1055. https://doi.org/10.1111/j.1475-679X.2008.00300.x

Blessing, S. (2011). Alternative alternatives: risk, returns and investment strategy (vol. 622). John wiley \& sons.

Boisclair, D., Lusardi, A., \& Michaud, P. C. (2017). Financial literacy and retirement planning in canada. Journal of pension economics \& finance, 16(3), 277-296. https://doi.org/10.1017/S1474747215000311

Bryman, A. (2011). Mission accomplished?: research methods in the first five years of leadership. Leadership, 7(1), 73-83. https://doi.org/10.1177/1742715010386864 


\section{Macrothink}

Enterprise Risk Management

ISSN 1937-7916

2020, Vol. 6, No. 1

Chen, L. (2015). Risk and experience in foreign direct investment decision making: evidence from chinese firms (doctoral dissertation, university of leeds). Retrieved from http://etheses.whiterose.ac.uk/11805/

Cottin, J. (1995). Tolerance at the risk of history - from voltaire to the present - french cornaton,m, editor. Etudes theologiques et religieuses, 70(4), 603-603.

Grable, J. E., \& Roszkowski, M. J. (2007). Self-assessments of risk tolerance by women and men. Psychological reports, 100(3), 795-802. https://doi.org/10.2466/pr0.100.3.795-802

Harris, J. R., Schiantarelli, F., \& Siregar, M. G. (1994). The effect of financial liberalization on the capital structure and investment decisions of indonesian manufacturing establishments. The world bank economic review, 8(1), 17-47. https://doi.org/10.1093/wber/8.1.17

Hastings, J. S., Madrian, B. C., \& Skimmyhorn, W. L. (2013). Financial literacy, financial education, and economic outcomes. Annu. Rev. Econ, 5(1), 347-373. https://doi.org/10.1146/annurev-economics-082312-125807

Lucarelli, C., Uberti, P., \& Brighetti, G. (2015). Misclassifications in financial risk tolerance. Journal of risk research, 18(4), 467-482. https://doi.org/10.1080/13669877.2014.910678

Lusardi, A. (2008). Financial literacy: an essential tool for informed consumer choice? (no. W14084). National bureau of economic research. https://doi.org/10.3386/w14084

Organizaion for economic cooperation \& devlopment (2011). Improving financial education efficiency proceedings from oecd bank of italy symposium on financial literacy.

Shoji, I., \& Kanehiro, S. (2012). Intertemporal dynamic choice under myopia for reward and different risk tolerances. Economic theory, 50(1), 85-98. https://doi.org/10.1007/s00199-010-0534-1

World bank group. (2011). World investment and political risk. Washington, d.c.: world bank.

\section{Note}

Note 1. See appendix for details 


\section{Macrothink}

\section{Appendices}

Appendix 1. Correlation Matrix

\begin{tabular}{lllll}
\hline Variables & $\begin{array}{l}\text { Investment } \\
\text { Decision }\end{array}$ & $\begin{array}{l}\text { Financial } \\
\text { knowledge }\end{array}$ & $\begin{array}{l}\text { Investment } \\
\text { Experience }\end{array}$ & $\begin{array}{l}\text { Risk } \\
\text { Tolerance }\end{array}$ \\
\hline Investment Decision & 1 & & & \\
Financial knowledge & .53 & 1 & & \\
Investment Experience & .34 & .114 & 1 & \\
Risk Tolerance & .67 & .010 & .714 & 1 \\
\hline
\end{tabular}

Appendix 2. Regression Analysis with-out Mediation

\begin{tabular}{lccccc}
\hline Variable & Coefficient & Std. Error & t-Statistic & Prob. & Results \\
\hline Constant & 1.125 & .051 & 22.277 & 0.000 & significant \\
Financial Knowledge & -.047 & .052 & -.737 & .462 & insignificant \\
Investment Exp & .494 & .022 & 3.127 & 0.000 & significant \\
Diagnostics & & & & & \\
R-Square & \multicolumn{2}{c}{0.485} & Adjusted R-squared & .417 & \\
F-statistic & \multicolumn{2}{c}{14.146} & Prob(F-statistic) & .0046 & \\
\hline
\end{tabular}

\section{Copyright Disclaimer}

Copyright for this article is retained by the author(s), with first publication rights granted to the journal.

This is an open-access article distributed under the terms and conditions of the Creative Commons Attribution license (http://creativecommons.org/licenses/by/3.0/). 